\title{
A Thermal Analysis and Optimization of a Combined Cycle by Several Technologies
}

\author{
KILANI Nihed*, KHIR Tahar, BEN BRAHIM Ammar \\ National School of Engineers of Gabes, University of Gabes Omar Ibn El Khattab St, 6029 Gabes, Tunisia, \\ *Corresponding author: nihedkilani@yahoo.com
}

Received March 26, 2014; Revised April 17, 2014; Accepted April 21, 2014

\begin{abstract}
Thermodynamic optimization of four power plant installations with different technology is presented and discussed in this paper. Numerical optimization of the different cycles is performed in aim to obtain higher efficiency. Thermal analysis performance for the fourth cycles is performed for a define range of operating parameters using a calculation code established according to EES software. The first studied cycle is a simple combined cycle containing gas turbine cycle with a steam injection system, one pressure heat recovery steam generator HRSG and a steam turbine cycle. The overall efficiency of this cycle in inlet ambient conditions is about $46 \%$. The second cycle is a combined one with steam injection system for which the steam injected is generated outside the HRSG using heat recovery system at the air compressor outlet. The performance of this cycle in the same initial conditions is higher of about $1 \%$. The third plant is a combined cycle with steam injection and two steam extractions from steam turbine and two open feedwater heaters. The performance of this cycle is higher of about $1 \%$ compared to the first one. The last considered power plant technology is a combined cycle with heat recovery at air compressor outlet and steam extraction. Obtained results show that the optimum operating parameters leading to the best performances are not the same for different cycles.
\end{abstract}

Keywords: combined cycle, steam extraction, heat recovery, optimization, thermal efficiency

Cite This Article: KILANI Nihed, KHIR Tahar, and BEN BRAHIM Ammar, "A Thermal Analysis and Optimization of a Combined Cycle by Several Technologies." American Journal of Energy Research, vol. 2, no. 2 (2014): 35-41. doi: 10.12691/ajer-2-2-3.

\section{Introduction}

Due to excessive demand for electricity new technologies are used for power plant cycle in aim to improve its performances. One of the major used resources is the fossil fuels.

Electricity production from fossil fuels has been known since 1936. Simple steam turbine cycles are firstly used with low thermal efficiency. Then the simple cycle is improved and combined with the gas turbine plant. Gas turbine cycle is very popular due to its relatively low capital cost, its significant reliability and flexibility, Basrawi et $\mathrm{Al}$ [1]. In the other hand considering evolutionary need for electricity many optimization and new power plants are carried out driving an evolution of the efficiency and produced net power. In addition the requirements of safety, environmental conditions and the excess of fuels price made the combined cycle more required because of its advantages in front of the other cycles Silveira et al. [2].

Several optimization studies, and research works were carried out [3,4]. Nord and Bolland [5] were developed new technologies to eliminate $\mathrm{CO}_{2}$ and improve the thermal efficiency for the same fuel flow rate used in traditional cycles. Sayyaadi and Mehrabipour [6] are used heat recovery system with tubular heat exchanger to improve the gas turbine cycle efficiency. Ibrahim et al [7] obtained an efficiency of $64.5 \%$ for a combined cycle with regeneration. Carcasci and Facchini [8] performed a comparison between two power plant installations with multi pressure HRSG and obtained a thermal efficiency of $60 \%$. Najjar et al [9] achieved a comparison between three processes for gas turbine blade cooling; the thermal efficiency of about $53 \%$ is obtained.

To minimize the emission of polluted gas and increase the gas turbine mass flow rate Bouam et al [10] used a steam injection system. That permitted an increase of the gas turbine cycle efficiency of about $0.11 \%$ for each $1 \%$ of steam injected.

This study is focused on the comparison between four combined power plants having the following design characteristics:

1. Simple combined cycle with steam injection.

2. Combined cycle with steam injection and compressed air cooling.

3. Combined cycle with steam injection into combustion chamber and steam extraction from the steam turbine.

4. The fourth considered plant is a combination between the second and third cycles.

\subsection{Simple combined cycle with steam injection}


The first cycle is a combination between a Brayton cycle with steam injection system in the combustion chamber and using natural gas as combustible and a steam turbine cycle. A mono pressure HRSG is installed at gas turbine outlet in order to generate the required steam flow rates for the steam turbine. The cycle is shown in Figure 1.

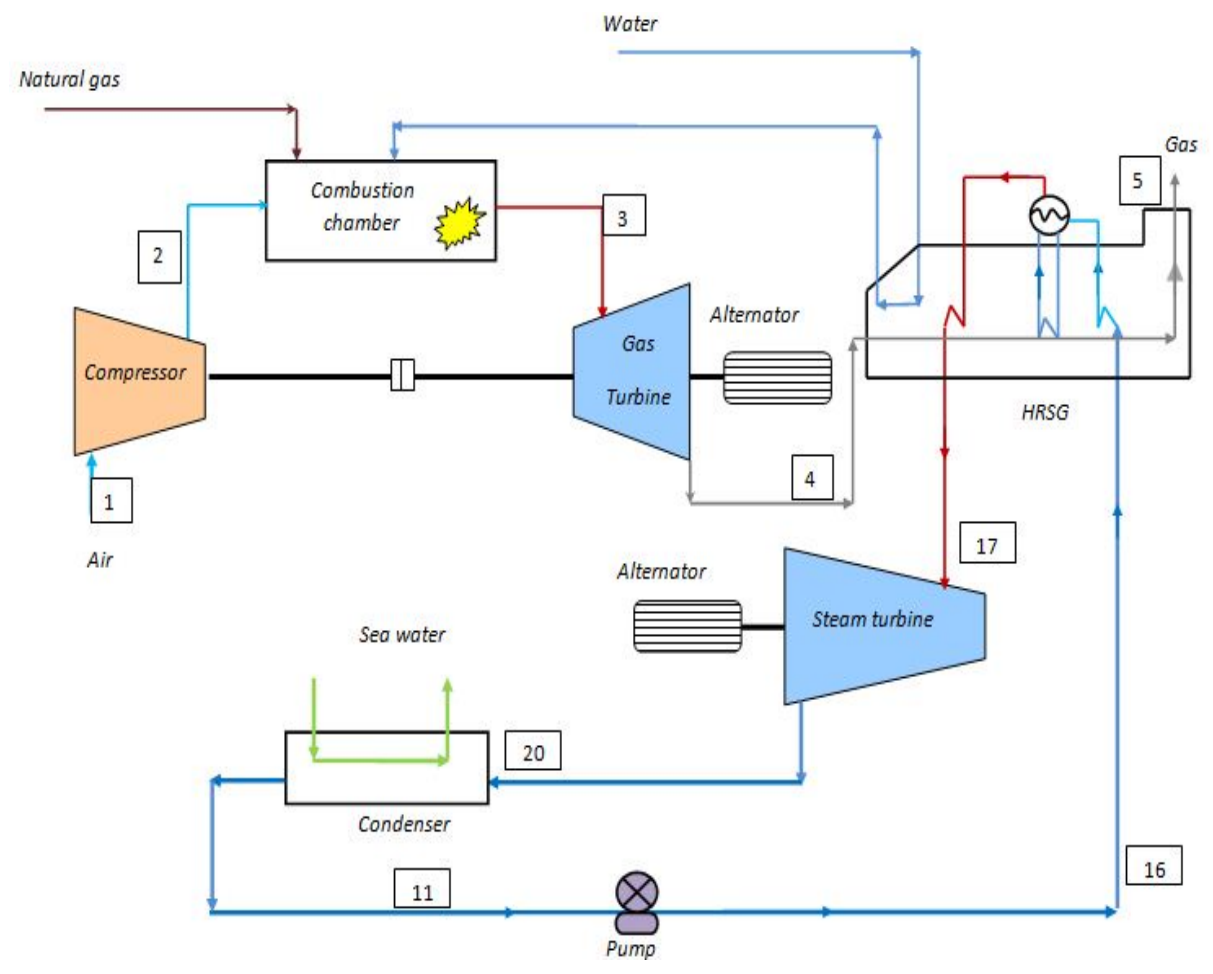

Figure 1. Simple combined cycle with steam injection

\subsection{Combined Cycle with Air Combustion Cooling}

For the second cycle, the steam injected in the combustion chamber is not produced in the HRSG as for the first installation but it is generated by a heat recovery system installed between the compressor and the combustion chamber. A heat transfer is made between compressed hot air and water. The compressed air is cooled and then entered into the combustion chamber. The supplied water is heated and evaporated in order to be injected into the combustion chamber as shown in Figure 2. This technique permits to increase the air density flowed through the combustion chamber. Thus the air mass flow rate increases, and consequently the gas turbine efficiency can be improved. In addition, steam generation is occurred outlet of the HRSG this can preserve more heat to the steam turbine cycle. Noting that a study is conducted by $B$. Glover study [11] on the metallurgy selection criterion of the heat exchanger used for this purpose.

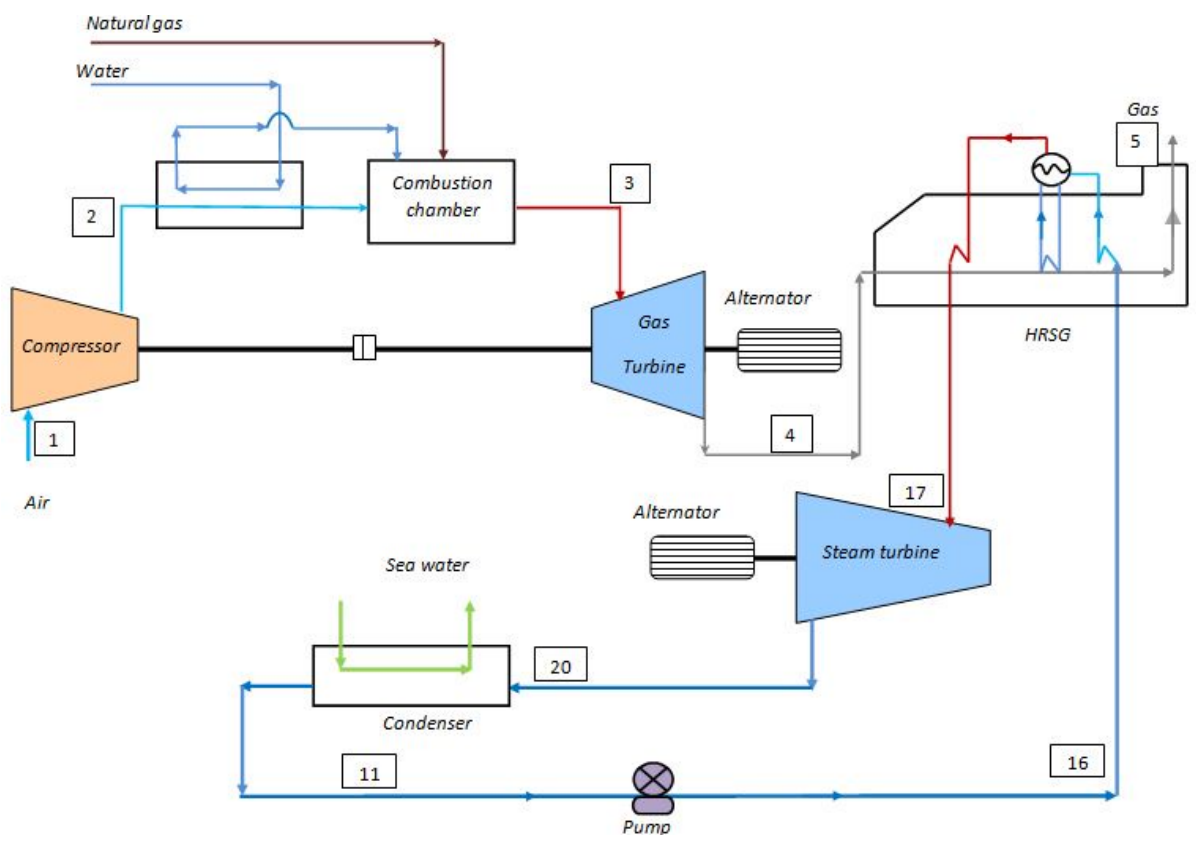

Figure 2. Combined cycle with air combustion cooling 


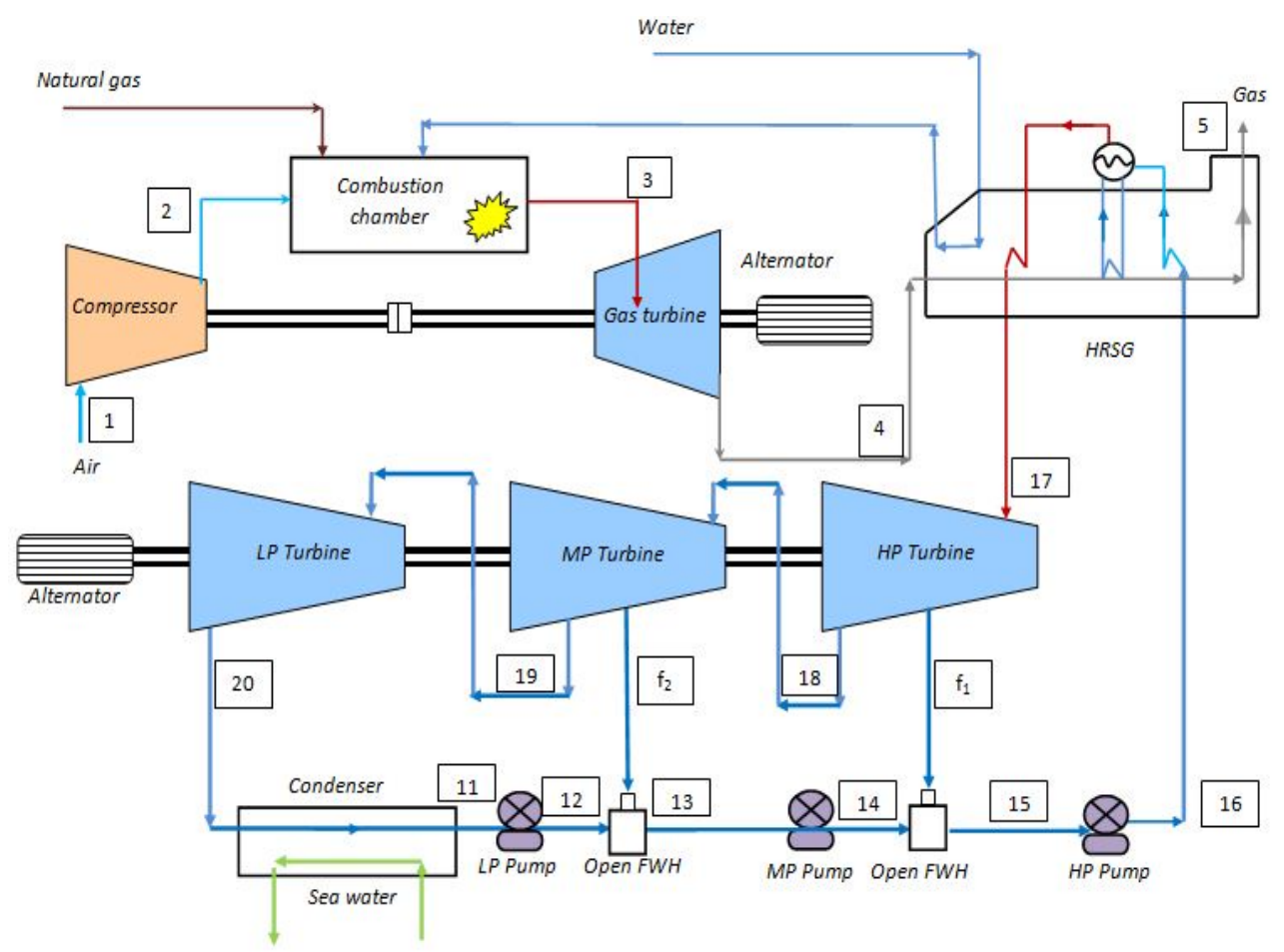

Figure 3. Combined cycle with steam extraction

\subsection{Combined Cycle with Steam Extraction}

In the third power plant steam is extracted from the steam turbine at two different pressure levels with two opened feed water heater as shown in Figure 3.

Steam extraction permits to reduce the flow rate through the condenser and consequently minimize its sizes. That can decrease the investment cost of the installation.

\subsection{Combined Cycle Power Plant with Steam Extraction and Compressed Air Cooling}

The fourth installation is a combination between the other studied power plants. It is a combined cycle with steam injection in the combustion chamber, compressed air cooling and two extractions from steam turbine. Despite of its important thermal efficiency, this installation is more complicated and need more control and regulation.

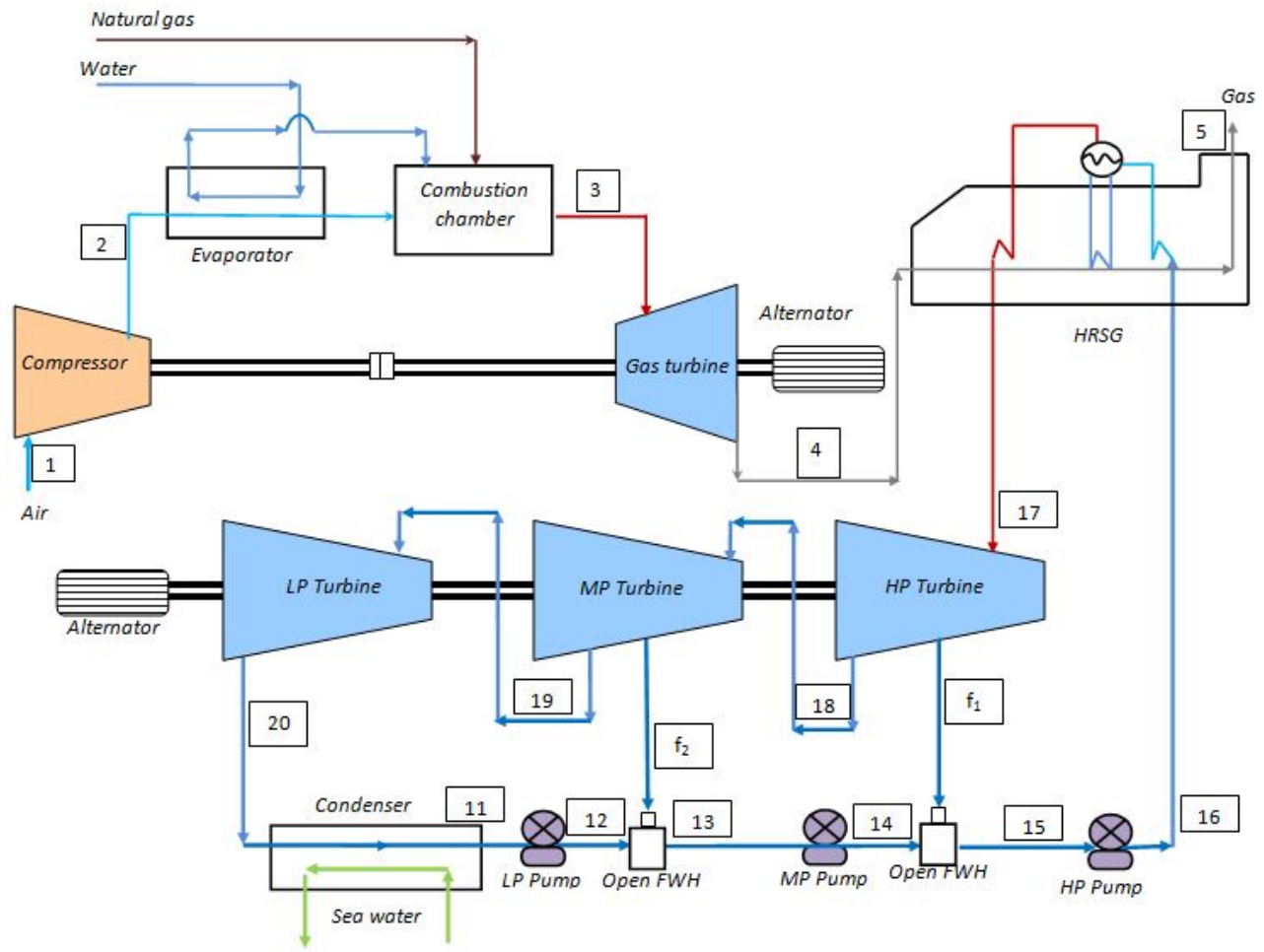

Figure 4. Combined cycle with steam extraction and compressed air cooling 


\section{Governing Equations and Heat Balance}

Governing equations and heat balance are widely expressed in several previous works [12,13,14]. In the following we present the main equations leading to define the thermal efficiency of the different considered cycles.

\subsection{Basic Installation}

\subsubsection{Air Compressor Equation}

For an isentropic compression isentropic outlet temperature is calculated according the following equation:

$$
T_{2 i s}=T_{1}\left(\frac{P_{2}}{P_{1}}\right)^{\frac{\gamma_{a}-1}{\gamma_{a}}}
$$

The compressor isentropic efficiency is given by:

$$
\eta_{\text {is Comp }}=\frac{T_{i s 2}-T_{1}}{T_{2}-T_{1}}
$$

The real outlet air temperature can be defined as:

$$
T_{2}=T_{1}+\frac{\left(T_{2 \text { is }}-T_{1}\right)}{\eta_{\text {iscomp }}}
$$

The need power compressor is calculated as:

$$
W_{\text {comp }}=\dot{m}_{\text {air }} \cdot C p_{\text {air }} \cdot\left(T_{2}-T_{1}\right)
$$

\subsubsection{Combustion Chamber Equation}

Energy balance in the combustion chamber can be established as follows:

$$
\begin{aligned}
& \dot{m}_{\text {fuel }} \cdot L H V \cdot \eta_{\text {combustion }}= \\
& \left(\dot{m}_{\text {air }}+\dot{m}_{\text {fuel }}+\dot{m}_{\text {steam }}\right) \cdot C p_{\text {gaz }} \cdot T_{3} \\
& -\dot{m}_{\text {air }} \cdot C p_{\text {air }} \cdot T_{2}-\dot{m}_{\text {fuel }} \cdot C p_{\text {fuel }} \cdot T_{\text {fuel }} \\
& -\dot{m}_{\text {steam }} \cdot C p_{\text {steam }} \cdot T \text { steam }
\end{aligned}
$$

For Tunisian natural gas used as gas turbine fuel, the Lower Heating Value is $\mathrm{LHV}=40546.25 \mathrm{KJ} / \mathrm{Nm}^{3}$.

The fuel flow used for cycle is calculated according to the following equation:

$$
\begin{aligned}
& f=\frac{\dot{m}_{\text {fuel }}}{\dot{m}_{\text {air }}} \\
& =\frac{C p_{\text {gaz }} \cdot T_{3}}{L H V \cdot \eta_{\text {combustion }}+C p_{\text {fuel }} \cdot T_{\text {fuel }}-C p_{\text {gaz }} \cdot T_{3}}+ \\
& \frac{C p_{\text {steam }} \cdot T_{\text {steam }}}{\dot{m}_{\text {air }}} \cdot \frac{C H V \cdot \eta_{\text {combustion }}+C p_{\text {fuel }} \cdot T_{\text {fuel }}-C p_{\text {gaz }} \cdot T_{3}}{L H}
\end{aligned}
$$

\subsubsection{Gas Turbine Equation}

For gas turbine and using the pressure ratio, the isentropic exit temperature is given by:

$$
T_{4 i s}=T_{3} \cdot\left(\frac{P_{2}}{P_{1}}\right)^{\frac{\gamma_{g}}{\gamma_{g}-1}}
$$

The real outlet temperature $\mathrm{T}_{4}$ is calculated by:

$$
T_{4}=T_{3}-\eta_{\text {isT }}\left[T_{3}-T_{4 i s}\right]
$$

Gas turbine produced power is determine by:

$$
W_{G T}=\dot{m}_{g} \cdot C p_{g a z} \cdot\left(T_{3}-T_{4}\right)
$$

The thermal efficiency of gas turbine cycle can be experimented as:

$$
\eta_{G C}=\frac{W_{G T}-W_{c o m p}}{Q_{c o m b}}
$$

\subsubsection{Steam turbine equation}

Steam cycle efficiency in the combined cycle is the ratio of net heat produced by the steam cycle and the heat of combustion produced in the combustion chamber.

$$
\eta_{S C}=\frac{W_{S T}-W_{\text {pumpe }}}{Q_{\text {comb }}}
$$

Where:

$$
\begin{aligned}
& W_{S T}=h_{17}-h_{20} \\
& W_{\text {pump }}=h_{16}-h_{11}
\end{aligned}
$$

\subsubsection{HRSG Equation}

The heat balance established for HRSG is ca be expressed by:

$$
\begin{aligned}
& \dot{m}_{\text {gaz }} \cdot C p_{\text {gaz }} \cdot\left(T_{4}-T_{5}\right)=\dot{m}_{\text {water }} \cdot C p_{\text {water }} \cdot\left(T_{\text {sat }}-T_{16}\right) \\
& +\dot{m}_{\text {steam }} \cdot C p_{\text {steam }} \cdot\left(T_{17}-T_{\text {sat }}\right) \\
& +\dot{m}_{\text {inj }} \cdot C p_{\text {inj }} \cdot\left(T_{\text {stea } \min j}-T_{\text {liqinj }}\right)+\left(\dot{m}_{\text {water }}+\dot{m}_{\text {inj }}\right) L_{v}
\end{aligned}
$$

The theoretical HRSG effectiveness is calculated by:

$$
\varepsilon_{\text {th }}=\frac{T_{4}-T_{\text {limit }}}{T_{4}-T_{\text {embiant }}}
$$

For the natural gas $\mathrm{T}_{\text {limit }}$ is taken between 70 and $100^{\circ} \mathrm{C}$ [11].

And the real HRSG effectiveness is given by:

$$
\frac{\varepsilon_{r}}{\varepsilon_{t h}}=\frac{T_{4}-T_{5}}{T_{4}-T_{\text {limit }}}
$$

\subsubsection{Condenser Equation}

The condenser the heat balance is expressed as:

$$
\dot{m}_{\text {sea }} \cdot C p_{\text {sea }} \cdot\left(T_{\text {out }}-T_{\text {in }}\right)=\dot{m}_{\text {steam }} \cdot\left(h_{20}-h_{11}\right)
$$

\subsection{Installation with Compressed Air Cooling}

\subsubsection{Water Evaporator}

In the heat exchanger installed between the air compressor and combustion chamber, water is heated and evaporated at high pressure and then injected into the combustion chamber. The heat transfer equation is expressed as: 


$$
\begin{aligned}
& \dot{m}_{\text {air }} \cdot C p_{\text {air }} \cdot\left(T_{\text {in }}-T_{\text {out }}\right) \\
& =\dot{m}_{\text {water }} \cdot C p_{\text {water }} \cdot\left(T_{\text {sat }}-T_{\text {in }}\right)+\dot{m}_{\text {water }} \cdot L_{v}
\end{aligned}
$$

\subsubsection{HRSG}

Since there is only one stream in the HRSG the heat balance becomes [15]:

$$
\begin{aligned}
& \dot{m}_{\text {gaz }} \cdot C p_{\text {gaz }} \cdot\left(T_{4}-T_{5}\right)=\dot{m}_{\text {water }} \cdot C p_{\text {water }} \cdot\left(T_{\text {sat }}-T_{16}\right) \\
& +\dot{m}_{\text {steam }} \cdot C p_{\text {steam }} \cdot\left(T_{17}-T_{\text {sat }}\right)+\dot{m}_{\text {water }} L_{v}
\end{aligned}
$$

\subsection{Installation with Steam Extraction}

\subsubsection{Steam Turbines}

The powers produced in the different steam turbine are defined as follows:

HP steam turbine:

$$
W_{S T 1}=\dot{m}_{\text {steam }} \cdot\left(h_{17}-h_{18}\right)
$$

MP steam turbine

$$
W_{S T 2}=\left(\dot{m}_{\text {steam }}-f_{1}\right) \cdot\left(h_{18}-h_{19}\right)
$$

LP steam turbine

$$
W_{S T 3}=\left(\dot{m}_{\text {steam }}-f_{1}-f_{2}\right) \cdot\left(h_{19}-h_{20}\right)
$$

\subsubsection{Pumps}

The energy required for the different pumps can be expressed by:

HP pump:

$$
W_{\text {pump } 1}=\dot{m}_{17} \cdot v_{15} \cdot \frac{\left(P_{16}-P_{15}\right)}{\eta_{\text {ispump } 1}}
$$

MP pump:

$$
W_{\text {pump } 2}=\left(\dot{m}_{17}-f_{1}\right) \cdot v_{13} \cdot \frac{\left(P_{14}-P_{13}\right)}{\eta_{\text {ispump } 2}}
$$

With $v$ is the water average specific volume.

LP pump:

$$
W_{\text {pump } 3}=\left(\dot{m}_{17}-f_{1}-f_{2}\right) \cdot v_{11} \cdot \frac{\left(P_{12}-P_{11}\right)}{\eta_{\text {ispump } 3}}
$$

\subsubsection{Feedwater Heater}

The operating conditions the FWH are defined such as the mixture leaving the FWH is at saturated liquid. For this reason extracted steam flow rates from both HP and MP turbines are calculated as follows:

$$
f_{1}=\dot{m}_{\text {steam }} \frac{h_{15}-h_{14}}{h_{18}-h_{15}}
$$

And

$$
f_{2}=\left(\dot{m}_{\text {water }}-f_{1}\right) \frac{h_{13}-h_{12}}{h_{19}-h_{13}}
$$

\section{Simulation and Interpretation of Cycles}

\subsection{Compression Ratio Influence}

The compression ratio effect on the overall cycle efficiency is mentioned in Figure 5. Numerical simulation for the different cycles is performed for the same operating conditions. The shapes of the overall cycle efficiency according to compression ratio agree with Rahman investigation [16].

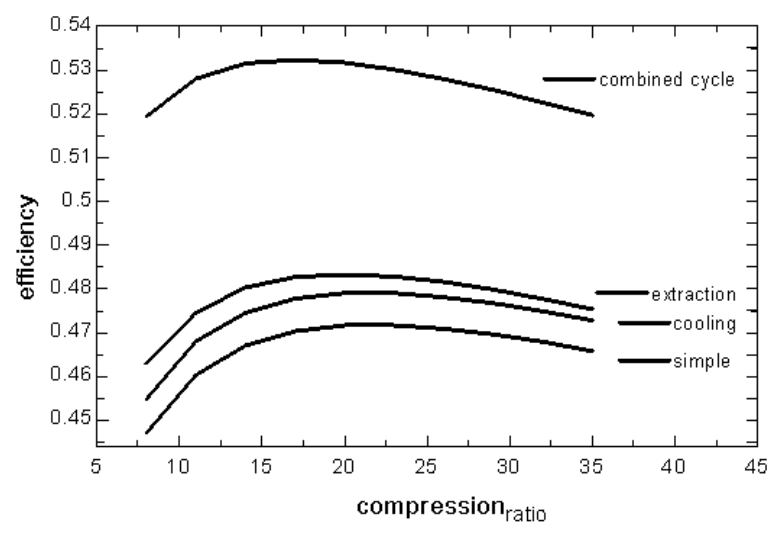

Figure 5. Cycle efficiency variations according compression ratio

Compressed air cooling process increases the cycle efficiency of about 1\% while the optimal compression ratio is same compared with the simple combined cycle. The steam extraction technology leads to an increase of the cycle efficiency of about $2 \%$ and a decrease the optimal compression ratio from 21 to 20. Combining compressed air cooling and steam extraction processes improve sensibly the cycle efficiency. The best cycle efficiency is about 53\% obtained for a compression ratio of 18 .

\subsection{Air Excess Influence}

The excess of air can assure a complete reaction in the combustion chamber, and reducing consequently the CO production. Also air excess contributes to the turbine blade cooling, avoids turbine blade corrosion and increases the gas flow rate. However increasing the air excess may decrease the gas turbine inlet temperature; which decreases the gas turbine cycle efficiency. The gas feeding the HRSG will be also cooled and the flux using for steam generation will be decreased. That affects the overall cycle efficiency.

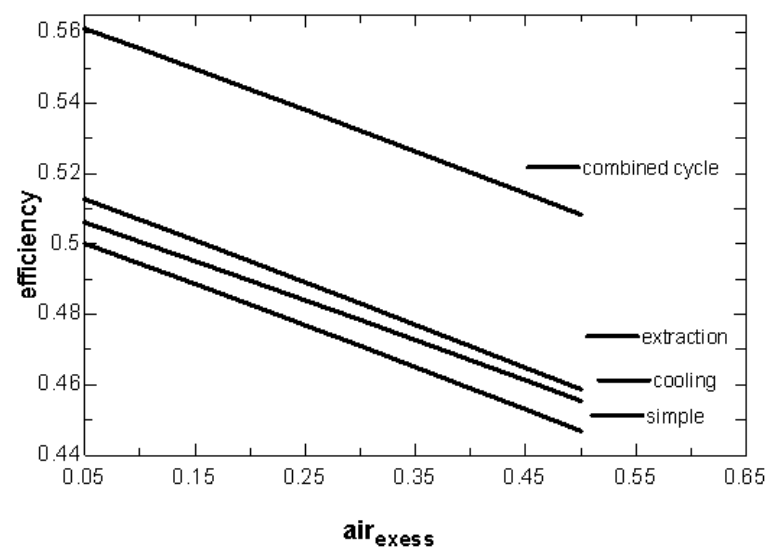

Figure 6. Air excess influence on the overall cycle efficiency of studied cycles

The variation of cycle efficiency according to air excess is shown in Figure 6 for the different considered cycles. Cycle efficiency decreases significantly with the increase 
of air excess. For air excess of $5 \%$ all cycles have best values of efficiency with $50 \%$ for the simple cycle and $56 \%$ for the fourth cycle. The choice of the optimal value of air excess is related to the gas turbine inlet temperature. Actually maximum temperature accepted by turbine blade is about $1873 \mathrm{~K}$.

The influence of air excess on the gas turbine inlet temperature TIT is presented in Figure 7. This temperature decreases significantly with the increase of air excess.

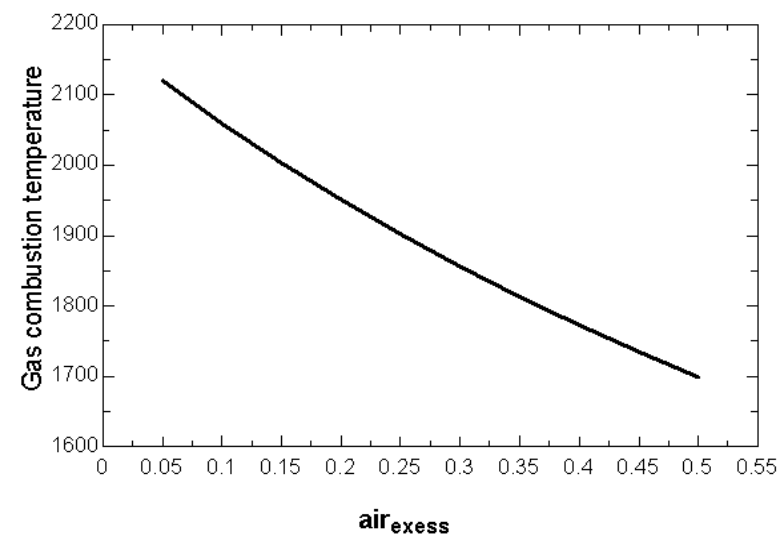

Figure 7. Gas Turbine inlet temperature with air excess

\subsection{Steam Injection Influence}

Steam injection in the combustion chamber is used to decrease $\mathrm{NO}, \mathrm{NO}_{2}, \mathrm{CO}$ emission. In other hand it's not recommended to attain more than $10 \%$ of steam injection rate due turbine blade protection.

The effect of steam injection on the cycle efficiency is shown in Figure 8. For simple cycle and cycle with steam extraction, steam injection has a negative effect on the overall cycle efficiency. This is can be explained by the fact that increasing steam injection flow rate leads to the increase of the heat flux provided by HRSG to transform water into steam. Thus the remained heat flux transferred to the steam turbine cycle is reduced.
For the simple installation, steam turbine cycle efficiency is too low. Consequently the decrease of the heat flux transferred to the steam turbine cycle reduces the overall cycle efficiency. But for combined cycle with steam extraction, steam turbine cycle is more efficient. Thus the overall cycle efficiency is better than the simple cycle efficiency and it decreases slightly with steam injection ratio.

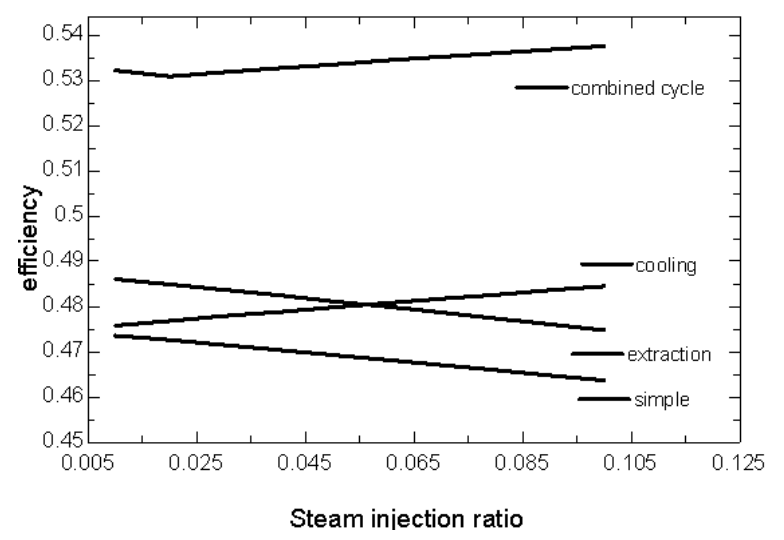

Figure 8. Steam injection influence on the cycle efficiency

For both the cycle with compressed air cooling and the fourth cycle, water heater-evaporator is installed at the compressor exit. A quantity of thermal energy is extracted from the compressed air and used to product steam for injection into the combustion chamber. The thermal energy transferred from gas turbine to the HRSG is integrally used for the steam turbine cycle. On the other hand the decrease of the compressed air temperature in the heat recovery system is neglected in the combustion chamber. Thus the overall cycle efficiency increases with steam injection ratio increase.

\subsection{Cycles Comparison}

Operating parameters and obtained results of the four considered power plants are arranged in Table 1.

Table 1. Operational parameters of studied cycle

\begin{tabular}{|c|c|c|c|c|}
\hline & $\begin{array}{l}\text { Simple combined } \\
\text { cycle }\end{array}$ & $\begin{array}{l}\text { Combined cycle with } \\
\text { compressed air cooling }\end{array}$ & $\begin{array}{l}\text { Combined cycle with } \\
\text { steam extraction }\end{array}$ & $\begin{array}{l}\text { Combined cycle with compressed air } \\
\text { cooling and steam extraction }\end{array}$ \\
\hline $\begin{array}{l}\text { Fuel: Natural gas } \\
\qquad(\mathrm{kg} / \mathrm{s})\end{array}$ & 18.63 & 18.4 & 18.17 & 16.47 \\
\hline $\begin{array}{l}\text { Inlet temperature } \\
\left({ }^{\circ} \mathrm{C}\right)\end{array}$ & 15 & 15 & 15 & 15 \\
\hline $\begin{array}{l}\text { Relative humidity } \\
\text { (\%) }\end{array}$ & 60 & 60 & 60 & 60 \\
\hline $\begin{array}{l}\text { Ambient pressure } \\
\text { (bar) }\end{array}$ & 1.013 & 1.013 & 1.013 & 1.013 \\
\hline Compression ratio & 20 & 18 & 18 & 18 \\
\hline Steam injection (\%) & 3 & 3 & 3 & 3 \\
\hline Air excess (\%) & 35 & 35 & 35 & 35 \\
\hline $\begin{array}{l}\text { Exhaust mass flow } \\
(\mathrm{kg} / \mathrm{s})\end{array}$ & 439 & 433.6 & 429.5 & 388.2 \\
\hline $\begin{array}{c}\text { Exhaust temperature } \\
\left({ }^{\circ} \mathrm{C}\right)\end{array}$ & 734 & 733 & 739 & 735 \\
\hline $\begin{array}{l}\text { Gas cycle output } \\
\text { (MW) }\end{array}$ & 320.857 & 316.670 & 312.254 & 290.521 \\
\hline $\begin{array}{l}\text { Steam cycle output } \\
\text { (MW) }\end{array}$ & 78.547 & 83.316 & 88.35 & 109.767 \\
\hline High pressure (bar) & 140 & 140 & 140 & 140 \\
\hline $\begin{array}{l}\text { Medium pressure } \\
\text { (bar) }\end{array}$ & - & - & 28 & 28 \\
\hline Low pressure (bar) & - & - & 3.5 & 3.5 \\
\hline Gross output (MW) & 401.002 & 401.680 & 400.589 & 400.288 \\
\hline $\begin{array}{c}\text { Overall cycle } \\
\text { efficiency (\%) }\end{array}$ & 46.59 & 47.24 & 47.7 & 52.59 \\
\hline
\end{tabular}




\section{Conclusion}

Thermal optimization study is performed on four different technologies of power plant combined cycles. Several processes are considered such as compressed air cooling, steam injection into combustion chamber and steam extraction. A comparison between the four combined cycles is developed for the same operating parameters. For each installation the influences of important parameters are analyzed.

Steam injection decreases the overall cycle efficiency if it generated in the HRSG. In the other hand, if a heat recovery system is externally added to generate steam for injection into the combustion chamber, the overall cycle efficiency increase with the increase of steam injection ratio.

Compression ratio presents an optimum of about 20 for the different plants. The technical modification added to the simple cycle leads to a slightly decrease of the optimal compression ratio.

Air excess decreases the overall cycle efficiency of the different installations due to its influence on the gas turbine inlet temperature. The heat fluxes extracted from turbine and transferred to steam cycle are reduced. In the other hand, air excess ratio is very important to protect turbine blade from corrosion and excessive temperatures. The optimum value of air excess ratio is mainly determined according to the desired gas turbine inlet temperature.

Steam ratio injected to the combustion chamber decreases the overall efficiency of the simple combined cycle and the combined cycle with steam extraction since the steam generation is realized in the HRSG. Thus increasing steam injection flow rate leads to the decrease of heat flux used for steam turbine cycle. If the steam is generated outside the HRSG, the steam injection into combustion chamber improves overall cycle efficiency.

\section{Reference}

[1] F. Basrawi, T. Yamada, K. Nakanishi, F. Naing, Effect of ambient temperature on the performance of micro gas turbine with cogeneration system in cold region, Applied Thermal Engineering 31, (2011), 1058-1067.

[2] J.L. Silveira, J.A. Carvalho, I.A. Villela, Combined cycle versus on thousand diesel power plants: pollutant emission, ecological efficiency and economic analysis, Renewable and Sustainable Energy Reviews 11, (2007), 524-535.

[3] Y.S.H. Najjar, Efficien use of energy by utilizing gas turbine combined systems, Applied Thermal Engineering 21, (2001), 407438.

[4] R. Felipe, P. Arrieta, E. Electo, S. Lora, Influence of ambient emperature on combined-cycle power-plant performance, Applied Energy 80, (2005), 261-272.

[5] L.O. Nord, O. Bolland, design and off-design simulation of combined cycles for offshore oil and gas installation, Applied Thermal Engineering 54, (2013), 85-91.

[6] H. Sayyaadi, R. Mehrabipour, Efficiency enhancement of a gas turbine cycle using an optimized tubular recupertive heat exchanger, Energy 38, (2012), 362-375.

[7] T.K. Ibrahim, M.M. Rahman, A.N. Abdalla, Optimum gas turbine configuration for improving the performance of combined cycle power plant, Procedia Engineering 15, (2011), 4216-4223.

[8] C. Carcasci, B. Facchini, Comparison between two gas turbine solutions to increase combined power plant efficiency, Energy Conversion \& Management 41, (2000) 757-773.

[9] Y.S.H. Najjar, A.S. Alghamdi, M.H. Al-Beirutty, Comparative performance of combined gas turbine systems under three different blade cooling schemes, Applied Thermal Engineering 24, (2004), 1919-1934.

[10] A. Bouam, S. Aissani, R. Kadi, Améliorationdes performancesdes turbines à gaz par injection de la vapeur d'eau en amontde la chambre de combustion, Revuedes Energies Renouvelables 11(2), (2008), 291-306.

[11] W.B. Glover, Selecting evaporator for process application, CEPmagazine, (2004), 26-33.

[12] M.P. Boyce, Gas turbine engineering handbook, Gulf Professional Publishing, (2002).

[13] J.H. Horlok, Advanced gas turbine cycles, Elsevier science, (2003)

[14] R. Kehlhofer, Combined cycle gas and steam turbine power plants, PennWell Company, (1997).

[15] V. Ganapathy, Heat Recovery Steam Generator: Understand the basics, Chemical Engineering (1996), 32-45.

[16] T.K. Ibrahim, M.M. Rahman, Effect of compression ratio on performance of combined cycle gas turbine 2(1), (2012), 9-14. 